\title{
Agnieszka Jelewska
}

ORCID: 0000-0003-2109-7545

Uniwersytet im. Adama Mickiewicza w Poznaniu

\section{Metafory i narzędzia planetarnej kolonizacji. Od pierwszego globusa do Earth System Science*}

Abstrakt: Celem tekstu jest spojrzenie na jedną z misji wpisanych w ramy nowożytności, czyli projektowania Ziemi jako całości, a więc postrzeganiu jej w kategoriach globu i planety. W eseju opisane zostały trzy projekty Ziemi traktowanej jako: globus, Statek Kosmiczny Ziemia i scalony system monitorowania środowiska (Earth System Science) tworzący cyborgiczną wizję planety. Choć różnią się one od siebie kontekstem historycznym, politycznym i technonaukowym zapleczem, przykłady te tworzą powiązaną sieć projektu Ziemia, w którym kolonializm i imperializm pierwszych odkrywców kontynuuje się w realizowanych od drugiej połowy XX wieku globalistyczno-kapitalistycznych koncepcjach definiowania planety jako sfery otwartej na możliwe modyfikacje i przekształcenia wpływające znacząco na funkcjonowanie całego ekosystemu.

Słowa-klucze: kolonizacja, środowisko, globalizacja, ekologia, projektowanie

W historycznej perspektywie widzenia kultury Zachodu projektowanie planety Ziemi, postrzeganej jako całość, wiązało się przede wszystkim z możliwościami technologicznymi, wyprawami pierwszych odkrywców, ale też narzędziami naukowymi i eksperymentami badawczymi, za pomocą których możliwe było tworzenie wizualizacji planety. Projektowanie każdorazowo stanowiło jednocześnie gest odtwarzania Ziemi, nie tylko w sensie wyobrażeń o jej możliwych kształtach,

* Tekst jest wynikiem badań prowadzonych w ramach grantu „Sztuka jako laboratorium nowego społeczeństwa. Kulturowe konsekwencje zwrotu post-technologicznego", finansowanego przez Narodowe Centrum Nauki, nr 2014/13/B/HS2/00508. Częściowe tezy zostały też opublikowane w tekście A. Jelewska, Spaceship Earth and the begninings of the new materialism, [w:] PostTechnological Experience: Art - Science - Culture, red. M. Krawczak, Poznań 2019, s. 28-38. 
granicach oraz sposobach funkcjonowania i relacjach na poziomie bytów ożywionych i nieożywionych, lecz także produkowania określonych metafor, które stały za rozwojem tych narzędzi. Poniższy tekst wskazuje trzy sposoby projektowania Ziemi w perspektywie traktowania jej jako całości, czyli globu.

Pierwszy to projekt Ziemi jako globusa. Ten sposób sprowadzenia planety do kuli dawał nowe możliwości zarówno opisu i mapowania terenu, jak i zarządzania ludźmi i nieludźmi. Sporządzenie globusa to ważna faza w historii ludzkiego postrzegania planety. Użyty przez tych, którzy podejmują odkrywcze wyzwanie, daje im zarazem przyzwolenie podporządkowywania i zawłaszczania „poznanego" świata poprzez gest wpisania w kartograficzne siatki globusa. Drugi to zestaw sposobów i funkcji projektowania, który ujęty został w amerykańskim programie o nazwie Statek Kosmiczny Ziemia, wprowadzający na skalę globalną model postrzegania Ziemi jako laboratorium, między innymi dla możliwych lotów kosmicznych oraz planów zasiedlania nowych planet. Trzeci projekt, rozwijający się współcześnie, to scalony system monitorowania Ziemi, stosowany pierwotnie przez NASA w latach osiemdziesiątych XX wieku. Obecnie jest on traktowany jako superdyscyplina naukowa, połączona $\mathrm{z}$ technologiczno-algorytmiczną infrastrukturą, dzięki której możliwe jest zarządzanie rozmaitymi parametrami planety. Wymienione przykłady łączy postrzeganie Ziemi z perspektywy holistycznej, globalnej; zawarta jest w nich tendencja do projektowania jako zarządzania i możliwości przekształcania planety na różnych poziomach.

\section{Globus jako medium praktyk kolonizacyjnych}

Historia globusa jako narzędzia wizualizacji i projektowania wyobrażeń o Ziemi może być zapewne rekonstruowana i interpretowana na wiele sposobów. Jedną z kluczowych konsekwencji i sprawczości, jaką kultura Zachodu wpisała w to narzędzie, jest bycie medium praktyk kolonizacyjnych, projektowanie Ziemi jako prawnej własności tego, który przybywa i odkrywa.

Większość badaczy uznaje, że pierwszy globus w kulturze śródziemnomorskiej powstał w II wieku p.n.e. Najprawdopodobniej sporządził go Krates z Mallos na podstawie obliczeń Eratostenesa z Cyreny, który około 250 roku p.n.e., zarządzając Biblioteką Aleksandryjską, spróbował zebrać dotychczasowe ustalenia i dane na temat kształtu i prawdopodobnych wymiarów Ziemi. Udało mu się wówczas także wyliczyć obwód Ziemi, choć opierał się na błędnych, jak dziś sądzimy, danych. Niemniej jednak jako pierwszy użył pojęcia „geografia, złożonego z Ge, co jest wariantem nazwy Gaia, i gráfein albo gráfo, co znaczy pisać, opisywać" . Znając obwód Ziemi, spróbował ustalić, jaką część planety stanowią

1 T. Reinertsen Berg, Teatr świata. Mapy, które tworza świat, przeł. M. Gołębiewska-Bijak, Kraków 2018, s. 59. 
obszary znane i zasiedlone (ekumena), a jaką te, których świat starożytny jeszcze nie poznał, tym samym stworzył pierwszą znaną mapę z siatką geograficzną. Rozwijając te ustalenia, Krates z Mallos opracował globus — pierwszy, jaki znamy - o średnicy około 3 metrów:

Na południu, zaraz pod równikiem leżała strefa antoikoi (tych, którzy mieszkają po przeciwnej stronie), po drugiej stronie półkuli północnej rozciągał się obszar perioikoi (tych, którzy mieszkają w pobliżu), a na południe od niej teren antipodes (tych, którzy chodzą do góry nogami). Kontynenty przedstawiono jako wyspy bez styczności ze sobą².

Sporządzenie pierwszego globusa wiązało się z możliwością przesunięcia zainteresowania własnym otoczeniem, kształtowania bezpiecznych endosfer, poznawania bliskiego kraju czy eksploatowania ziemi uprawianej wokół miejsca zamieszkania $\mathrm{w}$ stronę projektu eksploracji nieznanego. Jak pisał nieco później Ptolemeusz, komentując tę kwestię:

Z wszelkimi obszarami, o których jeszcze wszystkiego nie wiemy — bądź to dlatego, że są zbyt wielkie albo cały czas podlegają zmianom — jest tak, że w miarę upływu czasu rośnie nasza coraz dokładniejsza o nich wiedza. Tak samo jest z wykreślaniem mapy świata ${ }^{3}$.

Kolejne stulecia były zatem w różnym stopniu natężenia

zorganizowanymi działaniami nastawionymi na pozbycie się tego, co ukryte: żaden zabieg w dziejach ludzkości nie wypełnia tego określenia bardziej dramatycznie i wyczerpująco niż odkrywcza globalizacja Ziemi między XVI a XIX stuleciem ${ }^{4}$.

Pierwszy zachowany globus opracował w 1492 roku Martin Behaim, niemiecki kartograf, handlowiec i podróżnik, opierając się na wcześniejszych ustaleniach, szczególnie tych zebranych przez Ptolemeusza. To właśnie ten globus zainspirował Krzysztofa Kolumba do popłynięcia na Zachód ${ }^{5}$. Tym samym sukcesywnie opisywany i strukturyzowany glob stał się projektem poszerzania imperialnych wojen kolonizatorskich białych Europejczyków. Stałym elementem tej misji było zawłaszczanie kolejnych wielkości: wysp, ludów, roślin, zwierząt, całych połaci złóż minerałów, kontynentów, zatok poprzez użycie najpierw medium globusa, a potem coraz dokładniejszych map. Nowi przedsiębiorcy z pilotażowych narodów ekspansji, jak nazywa ich Peter Sloterdijk, oddzielają się od kraju urodzenia, ziemi, którą mogliby uprawiać, ucząc się nieustannie realizować swoje projekty $\mathrm{w}$ innych miejscach, w oderwaniu od punktu narodzin ${ }^{6}$.

2 Ibidem, s. 63.

${ }^{3}$ Cyt. za: ibidem, s. 64.

${ }^{4}$ P. Sloterdijk, Znaki odkrywców. O kartografii i czarach nazw imperialnych, [w:] idem, Kryształowy Pałac. O filozoficzna teorię globalizacji, przeł. B. Cymbrowski, Warszawa 2001, s. 124.

5 Tezę tę potwierdzał między innymi w cyklu wykładów wygłoszonych przed Maryland Historical Society John G. Morris, Martin Behaim: The German Astronomer and Cosmographer of the Times of Columbus, Baltimore 1855.

6 Zob. P. Sloterdijk, Czas globusa, czas światoobrazu, [w:] idem, Kryształowy Pałac..., s. 36. 
Behaim określił swój globus ,jabłkiem ziemskim”, w którym każde empiryczne miejsce potencjalnie staje się prymarnie ,adresem kapitału, który wszelkie punkty $\mathrm{w}$ przestrzeni widzi pod kątem ich osiągalności środkami technicznymi i ekonomicznymi"”. Według Sloderdijka globus Behaima i inne jego wersje wcześniejsze i późniejsze - tworzone aż do wieku XX — przekazują w gruncie rzeczy dosyć okrutne przesłanie, że „ludzie są żyjącymi istotami, które egzystują na skraju nierównego kulistego ciała, które jako całość nie jest ani matczynym łonem, ani naczyniem, ani nie daje schronienia" ${ }^{\prime}$. Na żadnym z globusów nie przedstawiono bowiem atmosfery. Dopiero wiek XX, dodając atmosferę, zmienił sytuację i postrzeganie Ziemi jako globu, przez co pojawiły się pierwsze oznaki załamania i wyczerpywania się projektu modernistycznej ekspansji nieznanego, do czego wrócę w dalszej części tekstu. Wcześniej glob był pozbawiony powietrza, zanurzony w nicości albo w pokoju bibliotecznym jego właściciela; pokazywał Ziemię skurczoną do kuli, umocowaną na drewnianej stopie i przytrzymywaną przez metalowy pierścień obiegający południki. Można było ją obracać i wskazywać palcem miejsce docelowe wyobrażonej bądź zrealizowanej wyprawy.

Obracanie globusa w europejskich domach kolonizatorów stało się znaczącym gestem symbolicznego posiadania Ziemi, czyli wyznaczania do jej podboju kolejnych narzędzi i projektów ekspansji. Warto przypomnieć, że aż do XVI wieku słowo „odkrywać” znaczyło zdjęcie zasłony z obiektu czy przedmiotu, a nie poznanie czegoś nowego, dopiero potem znaczenie rozszerzone zostało na to, co jest niepoznane. Dlatego Europejczycy renesansu, mówiąc o odkryciu (na przykład discovery, découverte, descumbrimiento), zawsze łączyli je z odnajdywaniem, znajdywaniem ${ }^{9}$, a przede wszystkim z mediami, takimi jak globus czy mapa, służącymi do ogłaszania zajęcia nowych terytoriów i ich utrzymywania. Były one traktowane jako uniwersalne narzędzia do zabezpieczania tego, co odkryte i będące już w posiadaniu tego, kto naniósł dany teren, obiekt, gatunek „,na globus". Informacji zbieranych było coraz więcej, dlatego bardzo szybko globus został uzupełniony przez mapy i projekty kartografii szczegółów, które zyskiwały istotniejsze znaczenie operacyjne, służąc między innymi jako „polityczne księgi wieczyste" 10 . Mapy legitymizowały bowiem w konsekwencji użycie innych środków do podporządkowywania, utrzymywania i tym samym terroryzowania, dokonywania albo zagłady, zniewolenia albo przesiedlania zarówno ludności, zasobów biologicznych, jak i złóż mineralnych danych obszarów w inne miejsca.

Co ciekawe, projekt ten postępował dość szybko - około 1600 roku Europejczycy nie znali nawet połowy tego, co nazywali globem. W 1800 roku dotarli już do czterech piątych obszarów planety, oczywiście bez świadomości tego, jak

\footnotetext{
${ }^{7}$ Ibidem, s. 38.

${ }^{8}$ Ibidem, s. 41.

9 Zob. P. Sloterdijk, Znaki odkrywców..., s. 125.

${ }^{10}$ Ibidem, s. 126.
} 
Ziemia funkcjonuje i na czym opiera się fenomen życia na tej planecie ${ }^{11}$. Pod koniec XX wieku Ziemia w badaniach astronomicznych i projektach kosmicznych wypraw skurczy się do rozmiaru piłeczki albo nawet kropki.

Historię globu jako znaczącego aktanta w projektowaniu Ziemi dubluje, a potem wypiera powstanie planisferycznej mapy świata. Zresztą, jak uznają badacze, transpozycja ta ma swoje źródła już w wieku XVII i wydaniu w Amsterdamie w 1608-1609 zbioru map nowożytności Gerardi Mercatoris Atlas sive cosmographicae meditationes de fabricati figura ${ }^{12}$. Sloterdijk uważa, że imperializm jest w zasadzie „stosowaną planimetrią, sztuką oddawania kul na płaszczyznach i światów w tabelach"13, w której ten, kto ma władzę, określa skalę i poziom spłaszczenia. Kolonizacja Europejczyków była równoznaczna z nadawaniem tytułów prawnych wynikających z tak zwanego aktu odkrycia. Zagarnianie globu w imię władcy zawsze wiązało się z ustanawianiem prawa, ale też stosowaniem zestawu rozmaitych rytuałów i implementowaniem symboli religijnych, flag i emblematów władcy, przede wszystkim zaś szkicowaniem map i nazywaniem ziem ${ }^{14}$. Dodajmy, że to tylko pierwszy etap projektowania własności ziemskich w skali globu, kolejny to zawłaszczanie innych jako niewolników, ich przymusowe migracje, przemieszczenia gatunków, a potem eksploatacja geologiczna samej ziemi, którą na szeroką skalę umożliwiła rewolucja przemysłowa, nakładając na mapę geofizyczną globu technologicznie, czyli infrastrukturalnie, możliwą do zrealizowania sieć przepływu szybszego kapitału, towarów i złóż mineralnych. Eksploatacja w głąb samej geologicznej struktury planety oraz rozwój gospodarki światowej opartej na węglu i ropie naftowej prowadzonej od XIX wieku, co w sposób bezpośredni przyczyniło się do pogłębiającego się kryzysu klimatycznego, ujawniły zmierzch projektu nowożytnego traktowania Ziemi jako globalnego projektu modernizacyjnego.

Bruno Latour, w trakcie seminarium przeprowadzonego w 2016 roku na Uniwersytecie w Aarhus ${ }^{15}$, wskazał istotną zmianę w projektowaniu Ziemi, która zaszła w XX i XXI wieku. Jako ludzkość egzystująca na planecie, twierdzi Latour, do czasów współczesnych oscylowaliśmy pomiędzy koncepcją Ziemi jako miejsca do uprawiania a niekończącym się projektem modernizacji i technologicznego przyspieszenia kolonizacyjnego, czyli pomiędzy ziemią uprawną a globem. Ostatnie dziesięciolecia i dane dotyczące zmian klimatycznych płynące od badaczy wielu dyscyplin wyczerpują modus projektowania jako niekończący się horyzont możliwości. Tym samym, stwierdza Latour, wracamy do Ziemi, Gai, systemu interakcji,

11 Ibidem, s. 125.

12 Zob. ibidem, s. 127.

13 Ibidem.

${ }^{14}$ C. Schmitt, Der Nomos der Erde, cyt. za: P. Sloterdijk, Znaki odkrywców..., s. 128.

15 B. Latour, Why Gaia is not the Globe: And why our future depends on not confusing the two, seminarium, 2.06.2016, The School of Culture and Society na Aarhus University w Dani, https:// www.youtube.com/watch?v=7AGg-oHzPsM (dostęp: 30.07.2019). 
którego jako ludzie jesteśmy częścią. Dopiero takie myślenie pozwoli nam spojrzeć na określone procesy krytycznie. Ale powrót do Ziemi, Gai, wcale nie jest jednoznaczny, ma też swoje kolejne liczne wersje i interpretacje. Jedną z nich jest ta, która jest łącznikiem między dawnymi koncepcjami globu i kolonizacyjnych wypraw a nowym postrzeganiem Ziemi jako systemu interakcji pomiędzy organizmami i ich otoczeniem. Jest to projekt Ziemi jako statku kosmicznego.

\section{Statek Kosmiczny Ziemia, czyli amerykańska wizja ekspansji \\ i przetrwania}

Na styku lat sześćdziesiątych i siedemdziesiątych XX wieku w ramach rodzących się koncepcji environmentalnych i różnych praktyk ekologicznych bardzo silnie wyartykułowane zostały wyzwania środowiskowe, przed którymi stanęła ludzkość w XX wieku, a więc wzrost zanieczyszczenia środowiska, zimna wojna wprowadzająca stan totalnego pokoju, jak o tym pisał Paul Virilio, i powiązane z nią ciągłe testy broni jądrowej (od pierwszego w Trinity Site w 1945 roku), szybki wzrost demograficzny, technologiczna i naukowa akceleracja (w 1969 roku amerykańscy astronauci lądują na Księżycu i wykonują pierwsze zdjęcia Ziemi z oddali), postępujące rozwarstwienie świata na kraje przyspieszające gospodarczo i technologicznie oraz te, które miały zostać poza czołówką (kraje Trzeciego Świata), wówczas także ma miejsce debata na temat eksploatacji zasobów Ziemi i ich potencjalnej skończoności, czego dowodem jest pierwszy poważny światowy kryzys naftowy z 1973 roku $^{16}$.

W tym właśnie czasie pojawił się nowy projekt definiowania Ziemi jako statku kosmicznego, w sposób oczywisty wyrastający ze wszystkich wymienionych zagrożeń, wyzwań i osiągnięć technonaukowych oraz polityki dwóch liczących się na arenie światowej mocarstw tkwiących w sytuacji zimnowojennej. Projekt Statku Kosmicznego Ziemia (SKZ), który został zapoczątkowany i wygenerowany w Stanach Zjednoczonych w latach sześćdziesiątych XX wieku, wpłynął w sposób znaczący nie tylko na politykę prowadzenia badań naukowych, rozwoju określonych technologii i konceptualizowania relacji człowiek-środowisko, lecz także w sposób istotny przyczynił się do wprowadzenia na skalę globalną postrzegania Ziemi jako laboratorium ${ }^{17}$. Wizja ta miała swoje technonaukowe podstawy oparte na szeroko rozumianej kategorii projektowania, w której daseinist design,

16 Zob. A. Jelewska, Ekotopie. Ekspansja technokultury, Poznań 2014.

17 Zob. M. Krawczak, Transforming the whole world into a laboratory: Cultural and artistic practices in the post-technological times, [w:] Post-Technological Experiences..., s. 98-110. 
jak ujął to Henk Oosterling ${ }^{18}$, staje się sposobem regulowania i przystosowywania społeczeństw ludzkich i nieludzkich oraz definiowania sił kosmopolitycznych, jak pisała o tym Isabell Stengers ${ }^{19}$.

W książce Spaceship Earth in the Environmental Age Sabine Hohler, niemiecka fizyczka, ale też historyczka nauki i środowiska, pisze, że wraz z przejęciem przez Stany Zjednoczone w drugiej połowie XX wieku europejskiego programu imperialistyczno-kolonizatorskiego pojawia się pojęcie unisfery zaproponowane już w latach pięćdziesiątych ${ }^{20}$. Unisfera — największy postały do tej pory fizyczny globus - miała łączyć zamożne uprzemysłowione kraje na zachodzie Europy i Ameryce Północnej, a także była wyrazem przekonania, że przyszłość świata opiera się na progresie szeroko pojętej idei westernizacji nie tylko Ziemi, ale też kosmosu. To właśnie unisfera dawała początek nowej polityce globalizacji, nowym kolonizatorom, którzy uznawali całą planetę za swoją własność. Amerykańskie prawo do ziemi miało stać się podstawą unifikacyjnych i technonaukowych programów planetarnych i pozaplanetarnych.

W tym właśnie czasie na początku lat sześćdziesiątych Richard Buckminister Fuller, amerykański architekt, kartograf, planista i filozof, na jednym ze swoich wykładów wygłoszonych w 1963 roku wprowadził opisowe pojęcie definiujące planetę jako Statek Kosmiczny Ziemia. W 1966 roku ukazała się praca Barbary Ward $^{21}$, brytyjskiej ekonomistki, zatytułowana Space Ship Earth, w której wskazuje ona na potrzebę wypracowania wspólnego balansu w rozwoju planetarnym, który ma być jednak zaproponowany i wdrożony przez kraje wysokorozwinięte; pisze też o Ziemi jako planecie zagrożonej szczególnie potencjalnym nuklearnym wybuchem, dlatego postuluje wprowadzenie nowych formy negocjacji między Zachodem i Wschodem. Projekt Ward wskazuje na potrzebę zrównoważanej eksploatacji zasobów ziemskich dla zachowania rodzaju ludzkiego na planecie.

Początkowo SKZ wydaje się metaforą, utopijną wizją, jednak bardzo szybko okazało się, że jest to nowy program globalnego przekształcenia, nie tylko na poziomie nauki czy technologii, lecz także ekonomii i — co najważniejsze nowej epistemologii, które od tej pory miały być domeną właśnie projektantów, naukowców i inżynierów. Kiedy w 1969 roku Fuller publikował swoją słynną broszurę Manual Operating for Spaceship Earth ${ }^{22}$, załoga Apollo 11 wylądowała już na Księżycu, wykonując słynne zdjęcia Ziemi jako niebieskiej marmurowej planety, które na zawsze zmieniły postrzeganie Ziemi, środowiska i relacji człowieka wobec kosmosu. Jednocześnie to właśnie ten moment utwierdził pro-

18 H. Oosterling, Dasein as Design or: Must Design Save the World?, przeł. L. Martz, The Nederland Institute for Design and Fashion, 2009, https://www.academia.edu/5862636/Dasein_as Design_Or_Must_Design_Save_the_World (dostęp: 15.04.2019).

19 I. Stengers, Cosmopolitics I, przeł. R. Bononno, Minneapolis 2010.

${ }^{20}$ S. Höhler, Spaceship Earth in the Environmental Age 1960-1990, London-New York 2016.

${ }^{21}$ B. Ward, Spaceship Earth, New York 1966.

${ }^{22}$ R. Buckminster Fuller, Operating Manual for Spaceship Earth, New York 1969. 
jektantów Statku Kosmicznego Ziemia w ich sile sprawczej wobec własnych założeń. W wymienionym tekście Buckminister Fuller szkicował niezwykle optymistyczny i entuzjastyczny obraz nowo odkrytej Ziemi. Planeta rozumiana była teraz jako całość, jako jeden organizm, funkcjonujący na zasadach teorii systemów, opartej na cybernetyce. Ta doniosła zmiana myślenia, unifikująca wszystkie elementy planetarnego układu w ramach systemowych, dawała możliwość ich przeprojektowania, a więc ingerencji $\mathrm{w}$ system, ale też włączanie różnych dyscyplin naukowych w badania $\mathrm{w}$ celu testowania środowiskowych uwarunkowań i wspólne rozwiązywanie problemów Ziemi. Fuller wierzył, że możliwe będzie w przyszłości zrezygnowanie z państw i narodowości, nie uznawał pojęcia rasy, widział wszystkich obywateli Ziemi jako załogę SKZ, zarządzaną przez naukowców, inżynierów, czyli nowo zdefiniowanych projektantów, którzy z jednej strony potrafią nawigować, znając teorię systemów, z drugiej wciąż odważnie inicjują, testują nowe rozwiązania poprawiające jakość życia na planecie. A ponieważ jest to planeta, która wchodzi w czas coraz silniej ujawniających się zagrożeń, również spowodowanych działalnością ludzką, musi być rozważnie zarządzana.

W swojej wizji Ziemi jako statku Fuller odwoływał się do figury Wielkich Piratów, którzy potrafili poza lądem i poza polityczno-religijnymi dyrektywami i epistemologicznymi przyzwyczajeniami dokonywać nowych odkryć i wypróbowywać nowe modele poznawcze, które doprowadzały ich do wytworzenia własnych pozalądowych dróg i form koegzystencji. Postulował ideę synergii, na której powinny opierać się badania transdyscyplinarne nad środowiskiem planetarnym.

Z koncepcją SKZ, wyrażaną przez Fullera i rozpropagowaną przez niego w całych Stanach Zjednoczonych, ale też w Europie, wiążą się również konkretne propozycje tak zwanego projektowania środowiskowego, dla którego modelem miały być stacje kosmiczne. W dużej mierze w projekcie SKZ mamy do czynienia z przekonaniem, że jeśli zrozumiemy sposób funkcjonowania środowiska jako systemów zależności i sprzężeń zwrotnych, będziemy mogli sterować tak zwanym zrównoważonym rozwojem całej planety — tutaj ważną rolę odegrały także prace architekta Iana McHarga i jego książka Design with Nature oraz koncepcja Ziemi jako samoregulującego się organizmu w wersji hipotezy Gai przedstawionej w latach siedemdziesiątych XX wieku przez Jamesa Lovelocka, o czym będzie mowa w dalszej części tekstu.

SKZ w swojej systemowej ontogenezie oferował ponadto strategię rozwoju w ramach ekonomii cyrkulacji i kapitalistycznego programu technonaukowej ekspansji. Już w 1966 roku Kenneth E. Boulding w cyklu bardzo szeroko komentowanych wykładów zatytułowanych The Economics of the Spaceship Earth opisywał moment, w którym znalazła się ludzkość, jako przejście od otwartej planety Ziemi do jej zamknięcia jako Statku Kosmicznego Ziemia ${ }^{23}$. Dla niego jako obywatela Stanów Zjednoczonych miało być to też przejście od ekonomii kowbojów, a więc agroekonomii lokalnej, do ekonomii astronautów, a więc tych,

${ }^{23}$ K.E. Boulding, The Economics of Coming Spaceship Earth, http://arachnid.biosci.utexas.edu/ courses/THOC/Readings/Boulding_SpaceshipEarth.pdf (dostęp: 20.04.2019). 
którzy widzą Ziemię jako całość, czyli ekonomii o wymiarze planetarnym, globalnym. Miała to być ekonomia oparta na ekologii systemowej, z jednej strony samoregulująca się, z drugiej — manipulowana i zarządzana, by utrzymać właściwy poziom cyrkulacji dóbr.

Kolejnym problemem wpisanym w projekt SKZ były nowe badania i statystyki demograficzne, które wieszczyły koniec Ziemi. W latach sześćdziesiątych i siedemdziesiątych nastąpił bardzo wzmożony rozkwit badań statystycznych dotyczących wzrostu populacji rodzaju ludzkiego. Jasne przecież było, że Ziemia jako statek ma swoje ograniczenia, dotyczące nie tylko eksploatacji jej zasobów, co może doprowadzić do jej wyczerpania, lecz także zbyt dużej liczby pasażerów, co może spowodować jej przeciążenie. Oczywiście kwestia ta nie była tak błaha - problem wiązał się przede wszystkim z wyżywieniem ,populacji ludzkiej” i zapewnieniem jej właściwych warunków egzystencji. To właśnie programowany model SKZ niejako wymuszał jednak na naukowcach krajów rozwiniętych nowe formy zarządzania zasobami ludzkimi w skali globalnej.

W 1968 roku powstała organizacja ZPG - Zero Population Growth — założona między innymi przez Paula Ehrlicha, autora słynnej książki Population Bomb. Organizacja ta podnosiła hasła zmniejszenia populacji światowej, wśród których znalazły się między innymi: „poprzestań na dwójce” i „kontroluj swoje lokalne gniazdo”. W 1969 roku został zainicjowany projekt United Nations Fund for Population Activities; organizacja finansowała ,pomoc w rozwiązywaniu problemów populacyjnych" w krajach rozwiniętych. Innym podejściem do problemu przeludnienia SKZ była propozycja Garretta Hardina, profesora biologii i ekologa z Uniwersytetu Kalifornijskiego w Santa Barbara, opisana w książce The Voyage of Spaceship Beagle i odnosząca się do słynnej historii Darwina. W czasie pięcioletniej podróży na statku „Beagle” Darwin rozwinął swoją wiedzę geologiczną i zebrał materiały do dalszych badań. Zaintrygowany problemami geograficznego rozmieszczenia okazów dzikiej przyrody i skamieniałości, które zebrał podczas podróży, badał zmiany, jakim ulegały gatunki, i w 1838 roku stworzył teorię doboru naturalnego. Według Hardina problemy przeludnienia populacji ludzkiej muszą być rozwiązane przy wprowadzaniu nowych standardów etycznych, które powinny zakładać możliwość sterowania doborem naturalnym ludzkiej populacji ${ }^{24}$.

Na słynnej i przełomowej konferencji Narodów Zjednoczonych w Sztokholmie w 1972 roku, zatytułowanej „Human Environment”, ten właśnie problem przeludnienia został bardzo wyraźnie zasugerowany, pojawiła się tam też figura Jednego Pokładu, na który powinni dostać się przedstawiciele wielu gatunków. Konferencja w Sztokholmie przyniosła też inne bardzo znaczące ustalenia. Niewiele już mówiło się o naturze, ale raczej o środowisku jako prawnym i naukowym obiekcie podlegającym międzynarodowym negocjacjom, administracji

${ }^{24}$ G. Hardin, Exploring New Ethics for Survival: The Voyage of Spaceship Beagle, London 1973. 
i procesom alokacyjnym. To nowo zdefiniowane środowisko było więc dostosowywane do badań, technologicznie monitorowane i zarządzane, był to zatem konstrukt głęboko polityczny i niezwykle mocno powiązany ze sferą rozwoju gospodarczego krajów zaawansowanych naukowo i technologicznie. Wprowadzając pojęcie środowiska, prelegenci sztokholmskiej konferencji wskazywali, że nie chodzi im o to, że człowiek ma być panem środowiska, ale o to, że jest on jego częścią, podlegającą tym samym sprzężeniom zwrotnym co sfera nieludzka w ramach gigantycznego planetarnego systemu. Sabine Höhler wskazuje jednak, że pojęcie „środowisko" w narracji sztokholmskiej sugerowało potencjalność, a nawet potrzebę bezpośrednich ludzkich ingerencji.

\section{Cyborgiczna Gaja, czyli Earth System Science}

James Lovelock, autor (we współpracy z Lynn Margulis) słynnej i szeroko dyskutowanej hipotezy $\mathrm{Gai}^{25}$, rozpoczynał karierę naukową między innymi jako twórca detektorów związków chemicznych dla NASA. Chęć przechwycenia oznak życia na innych planetach skłoniła go jednak do przemyślenia systemu funkcjonowania naszej planety. To, co ważne w projekcie Lovelocka, to przede wszystkim holistyczne i homeostatyczne ujęcie Ziemi jako superorganizmu tworzonego przez sprzężone interakcje pomiędzy wszystkimi biotami i elementami materii nieożywionej, jak powietrze, skały itp. W tej koncepcji, po pierwsze, bardzo ważną rolę odegrało myślenie Lovelocka o atmosferze jako swoistej skórze Ziemi, istotnym chemicznym zabezpieczeniu planety, które może według badacza podlegać homeostatycznym prawom działania całego sytemu. Po drugie, gatunek ludzki jest tylko jednym z wielu na planecie, wchodzącym w nieustanny system interakcji z pozostałymi gatunkami i elementami nieożywionymi. Gaja — jako nowy projekt systemowego traktowania Ziemi — „zarządza” całością. Wizja ta jest trudna do jednoznacznego zdefiniowania również dlatego, że Lovelock zmieniał ją i redefiniował jej elementy, począwszy od jej oryginalnej wersji $\mathrm{z}$ lat siedemdziesiątych. We wczesnych definicjach homeostaza, która dokonywała się poprzez i w celu funkcjonowania biosfery, była gwarantem wytwarzania się warunków, które - jak pisał Lovelock — były idealne do utrzymywania życia. W późniejszych wersjach uznaje on, że organizmy i ich materialne otoczenie ewoluują jako pojedynczy system, z czym powiązane jest utrzymanie samoregulacji klimatu i poziomu chemicznego w stanie pozwalającym na zamieszkanie dla tych biotów, które obecne są właśnie na planecie. Projekt Gaja ma jeszcze jedną interesującą warstwę - jest on połączeniem tego, co spekulatywne, naukowe, z tym, co kulturowe i mitologiczne. Tym samym jako koncepcja realizująca model syste-

25 Zob. m.in. J. Lovelock, Gaja. Nowe spojrzenie na życie na ziemi, przeł. M. Ryszkiewicz, Warszawa 2003. 
mowy obejmuje wiele aspektów życia na Ziemi, wraz z metapoziomami, jakimi są kultura i mitologie.

Kolejna ważna zmiana w myśleniu o Ziemi nastąpiła na przełomie wieków XX i XXI wraz z rozwojem możliwości zbierania i zarządzania danymi w skali planetarnej. Zmiana ta wykorzystała wizję systemowej i homeostatycznej Gai. W 1999 roku w czasopiśmie „Nature” ukazał się szeroko komentowany i wpływowy dla badaczy środowiska tekst Hansa Joachima Schellnhubera zatytułowany Earth system 'analysis and the second Copernican revolution ${ }^{26}$. Został on wydany w specjalnym numerze tego pisma z jednej strony poświęconym podsumowaniom wybitnych osiągnięć, które miały miejsce w XX wieku w poszczególnych dyscyplinach. $\mathrm{Z}$ drugiej jednak strony redaktorzy tomu prosili wybranych naukowców o opisanie tych elementów nauki, które będą miały istotny wpływ na badania w kolejnym milenium — Schellnhuber opisał sytuację nauk o środowisku. W artykule tym badacz wskazuje, że przewrót kopernikański XVI wieku przesunął Ziemię z centrum systemu słonecznego na pozycję jednej z wielu planet tego układu, jednak koniec wieku XX przyniósł drugą rewolucję — związaną z możliwościami monitorowania Ziemi, systemami zbierania danych i ich modelowania. Pierwsza rewolucja, dodaje Schellnhuber, osłabiała supremację Ziemi i rodzaju ludzkiego wobec potęgi kosmologii, druga - w swoim holistycznym ruchu — znów wprowadza tendencję do skupiania się na życiu ziemskim i warunkach środowiskowych; przywraca Ziemię w samo centrum ludzkiego uniwersum, co według Schellnhubera daje nowe możliwości jej badania i monitorowania jako całości.

Od kiedy pod koniec lat osiemdziesiątych NASA opublikowała Earth System Science (ESS) jako strukturyzujący koncept przyszłości badań, zaczęły pojawiać się coraz to nowsze sposoby studiowania Ziemi i środowiska planetarnego, skupione wokół różnych instytucji i organizacji. ESS nie tylko ma swoje podstawy w systemie monitorowania Ziemi z zewnątrz przez sieć satelitów, budowanie globalnej bazy danych i konstruowanie wysublimowanych modeli komputerowych, lecz także został uznany za holistyczną superdyscyplinę, która stara się ująć wszystkie procesy dotyczące środowiska ludzkiego i nieludzkiego jako połączony system. Przywołany w Earth system' analysis and the second Copernican revolution przez Schellnhubera model, znany jako diagram Brethertona, będaccy jednym z prototypowych dla rozwoju tej superdyscypliny, wskazuje możliwość rezygnacji z analizy poszczególnych podsystemów na rzecz spojrzenia hiperholistycznego, ujmującego system planetarny jako całość w ramach wiedzy zintegrowanej. Co istotne, aspekty dotyczące ludzkiej aktywności zostały tutaj potraktowane jako swoiste czarne skrzynki, niezdefiniowany obszar dociekań, stanowiący raczej element poboczny bądź podatny na potencjalną reorganizację $\mathrm{w}$ ramach nowego projektu zarządzania Ziemią. Schellnhuber proponuje porzucić proste

${ }^{26}$ H.J. Schellnhuber, Earth system' analysis and the second Copernican revolution, „Nature” 1999, nr 402, s. 19-23. 
myślenie kategoriami cybernetycznych sprzężeń pomiędzy podsystemami środowiska ziemskiego i wprowadzić ogólną formułę, która może być rozwijana i realizowana w różnych dyscyplinach w odmienny sposób. Formuła została wyrażona w tekście jako następująca zależność:

$$
\mathrm{E}=(\mathrm{N}, \mathrm{H})
$$

gdzie:

$\mathrm{N}=(\mathrm{a}, \mathrm{b}, \mathrm{c} \ldots)$;

$\mathrm{H}=(\mathrm{A}, \mathrm{S})$

E (Earth) - skomplikowane systemy tworzące środowisko ziemskie;

$\mathrm{N}$ (Nature/Ecosphere) - kolejno: a jak atmosfera, b jak biosfera, c jak kriosfera;

H (Human Factor) — czynnik ludzki, który może być analizowany przy użyciu dwóch podstawowych składowych: A (Anthroposhpere) - między innymi życie ludzkie, różne aktywności, produkcja, S (Self-reflecting global subject), czyli podmiot globalny, który tworzy rodzaj inteligencji środowiskowej świadomej zagrożeń zarówno na poziomie planetarnym, jak i lokalnym.

Brzmiąca być może utopijnie propozycja Schellhubera wprowadzenia do modeli analizy środowiska nie tylko ludzkiego czynnika jako czynnika biologicznego, lecz także refleksyjnego, czyli metafizycznego, kulturowego, społecznego, była próbą krytyki jednego z najważniejszych osiągnięć końca XX wieku, czyli Earth System Science, który w swoich podstawach był cybernetycznym modelem służącym produkowaniu wiedzy o środowisku i miał w kolejnym milenium stać się podstawą zasad jego globalnego zarządzania.

Rozwijający się obecnie w różnych instytutach na całym świecie projekt środowiska ziemskiego jako ESS pozostał raczej nowoczesną wersją konsekwencji Statku Kosmicznego Ziemia jako możliwości ciągłego monitorowania i tym samym eksperymentowania z kolejną próbą domestyfikowania całego środowiska ziemskiego poprzez system zbierania i interpretowania danych. Można zatem powiedzieć, że w długim trwaniu XX wieku przeszliśmy od koncepcji projektowania Ziemi i dla Ziemi, postrzegania planety jako mechanizmu, samoorganizującej się maszyny, statku nawigowanego przez projektantów, do Ziemi jako cyborga - planety poszerzonej o rozmaite interfejsy służące do zbierania i monitorowania danych. W zmianie tej warto zauważyć także przesunięcia w definiowaniu samej wiedzy o Ziemi, która współcześnie jest formą interpretacji danych przez systemy, czyli modele infrastrukturalno-algorytmiczne zbliżone do Earth System Science.

Przedstawione w tekście projekty i wizje planety Ziemi nie mają na celu skonstruowania linearnego przebiegu zmian pojęciowych i wygenerowanych wraz z nimi przekształceń polityczno-ekonomiczno-epistemologicznych. Są to wybrane, choć dość charakterystyczne i powszechne dla tych zmian, przykłady. Niestety pokazują dość spójny i konsekwentnie realizowany przez „przedsiębiorców z pilotażowych narodów ekspansji” projekt Ziemi jako własności tego, który odkrywa i prowadzi misję kolonizacyjną. Konstruowanie map przez Europejczyków 
i ich kolonizacyjny pochód doprowadziły do przemieszczania siłowego ludzi, gatunków roślin i zwierząt, transportowania złóż mineralnych, do czystek rasowych, niewolnictwa, kondycjonowania życia na plantacjach i geoinżynieryjnego przekształcania krajobrazu. Wszystkie te elementy tworzą powiązaną sieć projektu Ziemia, w którym kolonializm i imperializm, a potem ich globalistyczna kapitalistyczna wersja doprowadzają do eksterminacji samej planety. Sugerowany przez Latoura powrót do Gai czy promowany przez Schellnhubera projekt budowania nie tylko sieci monitorującej stan Ziemi, lecz także kształtowania polityki klimatycznej jako kolektywnej inteligencji ${ }^{27}$ nie mają już na celu poszerzania horyzontu projektowania planety, ale raczej są wersjami geomedycyny dla Ziemi, która jest już na oddziale intensywnej terapii. Wskazywanie zatem pewnych konsekwencji i źródeł historycznych współczesnej polityki klimatycznej wydaje się wciąż istotną pracą, zarówno na poziomie wielkich narracji na temat misji i realnych kolonizacyjnych masowych dewastacji, jak i skali lokalnych, w których często widać poziomy zniszczenia dokonane przez rozmaite formy najpierw zdobywania, potem mapowania, wreszcie - przeprojektowywania planety. W efekcie ujawniona zostaje też istotność systemowego włączania nauk humanistycznych i społecznych do badań nad rozpoznawaniem systemów projektowania i modelowania środowiska planety. Stosowane przez nowożytnych kolonizatorów i późniejszych projektantów modele analityczne, metafory poznawcze i formy ich wizualizacji w perspektywie globalnej kształtują wektor rozwoju nauki i cywilizacji. Dlatego też ważne i konieczne jest diagnozowanie nie tylko stanu biochemicznego Ziemi, lecz także politycznych i kulturowych agend stojących za tymi projektami.

\title{
Metaphors and instruments of planetary colonization: From the first globe to Earth System Science
}

\author{
Abstract
}

The purpose of the text is to look at one of the missions inscribed in the frame of modernity, that is, the design of the Earth as a whole, and thus perceiving it in terms of the globe and the planet. The essay describes three projects of the Earth treated as a globe, an Earth Spaceship, and an integrated Earth System Science creating a cyborg's vision of the planet. Although they differ from each other in their historical, political and scientific background, these examples form a connected network of the Earth project in which the colonialism and imperialism of the first explorers are continued in the globalist-capitalist concepts of defining the planet as a sphere open to possible modifications implemented since the second half of the 20th century and transformations significantly affecting the functioning of the entire ecosystem.

Keywords: colonization, environment, globalization, ecology, design

27 Zob. Anthropocene Lecture: Conversation with Bruno Latour and Hans Joachim Schellnhuber, 4.05.2018, HKW, Berlin https://www.youtube.com/watch?v=Z-n_44M2nLw (dostęp: 27.07.2019). 
Bibliografia

Anthropocene Lecture: Conversation with Bruno Latour and Hans Joachim Schellnhuber, 4.05.2018, HKW, Berlin, https://www.youtube.com/watch?v=Z-n_44M2nLw (dostęp: 27.07.2019).

Boulding K.E., The Economics of Coming Spaceship Earth, http://arachnid.biosci.utexas.edu/courses/THOC/Readings/Boulding_SpaceshipEarth.pdf (dostęp: 20.04.2019).

Buckminster Fuller R., Operating Manual for Spaceship Earth, New York 1969.

Diogenes Laertios, Żywoty i poglądy stynnych filozofów, przeł. I. Krońska, Warszawa 2004.

Hardin G., Exploring New Ethics for Survival: The Voyage of Spaceship Beagle, London 1973.

Höhler S., Spaceship Earth in the Environmental Age 1960-1990, London-New York 2016.

Jelewska A., Ekotopie. Ekspansja technokultury, Poznań 2014.

Jelewska A., Spaceship Earth and the begninings of the new materialism, [w:] Post-Technological Experience: Art - Science - Culture, red. M. Krawczak, Poznań 2019.

Krawczak M., Transforming the whole world into a laboratory: Cultural and artistic practices in the post-technological times, [w:] Post-Technological Experiences: Art - Science - Culture, red. M. Krawczak, Poznań 2019.

Latour B., Why Gaia is not the Globe: And why our future depends on not confusing the two, seminarium, 2.06.2016, The School of Culture and Society na Aarhus University w Dani, https://www. youtube.com/watch?v=7AGg-oHzPsM (dostęp: 30.07.2019).

Lovelock J., Gaja. Nowe spojrzenie na życie na Ziemi, przeł. M. Ryszkiewicz, Warszawa 2003.

Morris J.G., Martin Behaim: The German Astronomer and Cosmographer of the Times of Columbus, Baltimore 1855.

Oosterling H., Dasein as Design or: Must Design Save the World?, przeł. L. Martz, The Nederland Institute for Design and Fashion, 2009, https://www.academia.edu/5862636/Dasein_as_Design Or Must Design Save the World (dostęp: 15.04.2019).

Reinertsen Berg T., Teatr świata. Mapy, które tworza świat, przeł. M. Gołębiewska-Bijak, Kraków 2018.

Schellnhuber H.J., Earth system' analysis and the second Copernican revolution, „Nature” 1999, nr 402.

Sloterdijk P, Kryształowy Pałac. O filozoficzna teorię globalizacji, przeł. B. Cymbrowski, Warszawa 2001.

Stengers I., Cosmopolitics I, przeł. R. Bononno, Minneapolis 2010.

Ward B., Spaceship Earth, New York 1966.

Prace Kulturoznawcze 23, 2019, nr 2-3

(C) for this edition by CNS 